\title{
Avaliação do desempenho da atenção básica no Estado de São Paulo
}

\author{
Care performance assessment of primary \\ health care services in the State of São Paulo
}

Nelson Ibañez 1

Juan S. Yazle Rocha 2

Paulo Carrara de Castro 1

Manoel Carlos Sampaio de Almeida Ribeiro 1

Aldaisa Cassanho Forster 2

Maria H. D. Novaes 3

Ana Luiza d'Avila Viana ${ }^{3}$

1 Departamento de Medicina Social, Faculdade de Ciências Médicas da Santa Casa de São Paulo Rua Dr. Cesário Motta Jr., 61/5o andar, Vila Buarque, 0122-010 São Paulo SP. nibanez@butantan.gov.br

2 Departamento de

Medicina Social,

Faculdade de Medicina

de Ribeirão Preto.

${ }^{3}$ Departamento de

Medicina Preventiva,

Faculdade de Medicina, USP.
Abstract The objective of this article is to present the results of the care performance assessment of primary care services in a selected sample of municipalities with more than 100 thousand inhabitants in the State of São Paulo. These municipalities were grouped into clusters. Patients and primary care providers from traditional units and Family Health Programs (FHP) were interviewed using specific questionnaires which covered the eight dimensions of primary care. Regarding the assessment made by Patients and Companions, the general index obtained was 50\%, which in a way qualifies it as not very satisfacto$r y$. As for the analysis by dimensions, there is a greater level of satisfaction in the clusters with more favorable social indicators in all the studied dimensions except for the Services Available and Community Advising. Regarding the assessment made by primary care providers in traditional units and FHP, the primary care providers who work in the FHP evaluate the performance as better. In municipalities with less favorable social indicators, it is possible to evidence that the dimensions of linkages, services available, family focusing and community advising were better assessed by the FHP providers.

Key words Primary care, Performance assessment, Family Health Program
Resumo O objetivo do artigo é apresentar os resultados da avaliação de desempenho da atenção nos serviços de Atenção Básica numa amostra selecionada de municípios do Estado de São Paulo com mais de 100 mil habitantes agrupados em clusters, por meio de questionários específicos abordando oito dimensões da atenção básica. A avaliação feita por usuários e acompanhantes aponta o indice geral de 50\%, o que qualifica como pouco satisfatória. Quanto à análise por dimensões há maior nível de satisfação nos clusters com indicadores sociais mais favoráveis em todas as dimensões estudadas, com exceção de elenco de serviços e orientação comunitária. Em relação à avaliação dos trabalhadores da saúde de unidades tradicionais e PSF, mostrou que os profissionais que trabalham no PSF avaliam o desempenho como sendo melhor. Nos municípios com indicadores sociais menos favoráveis é possível evidenciar que as dimensões vínculo, elenco de serviços, enfoque familiar e orientação comunitária foram mais bem avaliadas pelos profissionais do PSF.

Palavras-chave Atenção Básica, Avaliação de desempenho, Programa de Saúde da Família 


\section{Apresentação}

Este artigo se insere na série de estudos realizados no Brasil a partir do projeto proposto pelo Ministério da Saúde - "Monitoramento e Avaliação do Projeto de Expansão e Consolidação do Saúde da Família (Proesf) para o Desenvolvimento de Estudos Avaliativos - Linhas de Base - de Municípios" (Estudo I) e "Estudo Amostral do Impacto do Proesf" (Estudo II).

O estudo envolvendo os 62 municípios com mais de 100 mil habitantes no Estado de São Paulo foi desenvolvido por um consórcio coordenado pela Faculdade de Medicina da USP, envolvendo mais cinco instituições de ensino e pesquisa (Faculdade de Medicina de Ribeirão Preto/USP; Cealag - Departamento de Medicina Social FCMSCSP; Cedec; Fundação Vanzolini/USP; UFRJ).

\section{Introdução}

$\mathrm{Na}$ análise da trajetória histórica da Atenção Primária em Saúde (APS) no Brasil nos últimas décadas, Fausto ${ }^{1}$ identifica três fases na ação governamental e produção de conhecimentos. Uma primeira, centrada no desenvolvimento de programas docente-assistencial e de extensão de cobertura e estudos pioneiros sobre medicina preventiva e análise de programas orientados pelos princípios da medicina comunitária. $\mathrm{Na}$ segunda fase a perspectiva da ação se desloca para os sistemas locais de saúde e definição de princípios e estratégias para a reforma sanitária, e os estudos enfocam mais a democratização, universalização e descentralização no campo da saúde, com uma retração nos estudos da APS. A fase mais recente se caracteriza por dois momentos, com um foco inicial na descentralização das ações de saúde e proposição de programas seletivos inseridos na atenção primária e o posterior desenvolvimento do Programa de Saúde da Família como estratégia de reorientação do modelo de atenção do Sistema Único de Saúde (SUS), que passa e ter ênfase na atenção primária.

Levcovitz et al. ${ }^{2}$ observam, referenciandose às novas políticas de reorientação do modelo de atenção a partir do PSF e aos dilemas enfrentados no processo de desenvolvimento destas, o crescimento dos estudos sobre o próprio programa e a discussão mais ampliada sobre a vigilância à saúde.

No entanto, uma revisão sobre as publicações científicas sobre APS no Brasil no período de 1990 a 2001 mostra que, apesar do crescimento no número de estudos, apenas $9 \%$ destes discutem a APS na perspectiva do sistema de saúde, sendo a maioria com enfoque clínico ou de serviços de saúde 3 .

Ao se referir a este tema, Almeida et al. 4 dizem que se podem identificar quatro tipos de pesquisas: 1) estudos de caso, incluindo teses de doutorado ou mestrado, sobre a implementação de um programa específico ou de uma política de atenção básica; 2) grandes pesquisas sobre a implementação do Programa de Saúde da Família (PSF) em vários municípios (que é a maioria); 3 ) pesquisas sobre o funcionamento de um serviço específico ou processo de trabalho na atenção básica, como trabalho em equipe, ou ainda atenção a uma doença especifica; e 4) análises históricas sobre o desenvolvimento da política de atenção básica ou de programas especiais (principalmente o Programa de Agentes Comunitários de Saúde - Pacs e PSF).

A compreensão da atenção básica está permeada pelas dimensões econômica, políticas e culturais inerentes ao campo da saúde. Por este motivo, buscar o seu significado no âmbito da política de saúde exige um resgate histórico e político de sua conformação, o que nos permite capturar sua representação à luz dos diferentes atores sociais, seus interesses e finalidades, em diferentes contextos e épocas.

No Brasil, uma das raízes da atenção primária em saúde está relacionada ao movimento da medicina preventiva, desencadeado com maior vigor a partir da reforma do ensino médico norte-americano, nos anos 40.5

Partindo de uma abordagem integral, a medicina preventiva propôs uma atenção em que o indivíduo sob assistência médica deveria ser considerado a partir das interfaces sociais, culturais de sua realidade. A atenção médica, em sua fase inicial, deveria se fazer mais próxima do ambiente sociocultural dos indivíduos e famílias, o que respaldaria sua intervenção para a prevenção e controle do adoecimento. Esta concepção será fundamental para formar a base das práticas de atenção primária em saúde, conjugando duas questões essenciais: a atenção que se faz em primeiro lugar e que se faz mais próxima do cotidiano, do ambiente sociocultural dos indivíduos e das famílias.

O conjunto de idéias formulado pela medicina preventiva influenciou de maneira importante uma série de medidas e propostas de atenção primária em saúde, principalmente a partir dos anos 60. Formou-se, então, uma cul- 
tura sobre os diferentes momentos da atenção, em que a atenção primária se localiza na fase inicial do cuidado, antecedendo e definindo uma série de outros cuidados que deverão ser ofertados por outros níveis de atenção mais complexos.

A atenção primária em saúde surge, portanto, de um movimento de formação médica e só posteriormente será remetida ao campo de competências dos serviços de saúde e a organização de suas ações. Sob o signo da medicina preventiva, a medicina comunitária fundamentou e desenvolveu a atenção primária através de programas docente-assistenciais, conciliando formação médica e ações de saúde com a comunidade. Estas experiências provocaram uma extensa reflexão a respeito da insuficiência e desigualdade na distribuição e uso dos recursos em saúde, principalmente no que se refere à exclusão dos grupos sociais mais vulneráveis.

Se os anos 60 foram marcados pela disseminação do ideário da medicina preventiva e das práticas de atenção primária oriundas principalmente do meio acadêmico, os anos 70 se destacaram pela institucionalização de programas nessa linha. É assim que a atenção primária ganha espaço na agenda governamental, tendo a Organização Mundial da Saúde (OMS) como uma das principais agências difusoras deste ideário, juntamente com outros organismos de cooperação internacional, culminando com a Conferência de Alma-Ata em 1979, em que a APS foi considerada a principal estratégia para se atingir o objetivo de "Saúde para todos no ano 2000"6

Os programas de extensão de cobertura foram os principais mecanismos de veiculação da medicina comunitária e, nessa perspectiva, a atenção primária era interpretada como um conjunto de ações elementares que todos os serviços de saúde, até os mais simples, deveriam estar capacitados para prover. No centro destas ações estava a atenção médica, e a execução das práticas de promoção da saúde era fundamentalmente promovida por pessoas vinculadas às próprias comunidades, treinadas pelos profissionais de saúde.

O histórico das abordagens nesta área aponta a emergência da atenção como mecanismo de ampliação de acesso aos serviços indispensável para a manutenção da saúde dos indivíduos. Como primeiro nível de atenção deve conectar-se a outros níveis do cuidado, pressupondo uma rede integrada de serviços de saúde. Por outro lado, a institucionalização das práticas de atenção primária, desde seus primór- dios, está associada à resposta governamental para enfrentamento do custo da assistência médica, focada na aplicação de maior racionalidade no uso dos serviços de saúde de forma a torná-los mais produtivos, menos custosos e mais abrangentes.

Os aspectos econômicos, políticos e ideológicos que permeiam as práticas no campo da saúde produziram distintas interpretações e abordagens sobre o significado da atenção básica nos diferentes sistemas de saúde. Além desses aspectos, o termo "primário", que tem cunhado a noção de atenção básica, traz em si diferentes possibilidades explicativas, o que provoca confusão, ambigüidade e falta de consenso em torno de seus propósitos.

Estas questões intrínsecas às características da atenção básica têm implicações importantes na forma como os sistemas de saúde enfrentam e encaminham suas ações. Tarimo \& Webster ${ }^{7}$ relacionam diferentes definições e formas de interpretação sobre atenção básica desenvolvida ao longo do tempo e em diferentes lugares, as quais, para os autores, significam interpretações incompletas ou até mesmo errôneas a respeito dos princípios fundamentais do cuidado primário em saúde.

De acordo com os autores, cuidado primário em saúde pode ser entendido:

1. somente como community-based health care, sem a perspectiva de alteração nos demais níveis do sistema de saúde, como requereria uma abordagem mais ampla da atenção primária;

2. principalmente como primeiro nível de contato dos indivíduos e comunidades com o sistema de saúde, com pouca ênfase aos princípios subjacentes aos cuidados primários em saúde; 3. somente para os pobres nos países em desenvolvimento, que não dispõem de recursos próprios para acessar serviços médicos;

4. como núcleo de um conjunto de serviços de saúde, sendo estabelecido um "mínimo" de atividades consideradas essenciais que o sistema de serviços de saúde deve prover, podendo haver a exclusão de outros elementos importantes para o cuidado em saúde;

5. dirigido somente para áreas rurais, com intervenções simples, low-tech, feitas por trabalhadores de limitado conhecimento e treinamento, fazendo oposição aos médicos, hospitais e ao uso de tecnologias modernas;

6. como um cuidado de baixo custo, visto como um caminho relativamente barato para desenvolver sistemas de saúde, principalmente em países pobres. 
Considerando a diversidade de sistemas de serviços de saúde existentes, Vuori, apud Starfield, 8 apresenta quatro diferentes pontos de compreensão sobre a atenção básica: um conjunto de atividades, um nível de assistência, uma estratégia de organização do sistema de serviços e uma filosofia. Para a autora, as citadas interpretações sobre a atenção básica não são excludentes e podem coexistir em um mesmo sistema de saúde. A autora parte da compreensão de que não existe uma única forma de delimitação das práticas primárias em saúde. Mas, a atenção primária, ao se apresentar como um conjunto de funções combinadas, é exclusiva e caracteriza este nível de atenção. É uma abordagem que forma a base e determina o trabalho de todos os outros níveis do sistema de saúde, organizando e racionalizando o uso de todos os recursos, tanto básicos como especializados, direcionados para a promoção, manutenção e melhora da saúde. Macinko e Starfield ${ }^{9}$ elaboraram a seguinte definição para atenção primária: Aquele nível de um sistema de serviço de saúde que funciona como porta de entrada no sistema, atendendo a todas as necessidades e problemas de saúde da pessoa (não direcionadas apenas para a enfermidade), ao longo do tempo, fornece atenção para todas as condições, exceto as muito incomuns ou raras, e coordena ou integra os outros tipos de atenção fornecidos em algum outro lugar ou por terceiros. Assim, é definida como um conjunto de funções que, combinadas, são exclusivas da atenção primária... A atenção primária aborda os problemas mais comuns da comunidade oferecendo serviços de prevenção, cura e reabilitação... Ela integra a atenção quando existem múltiplos problemas de saúde... É a atenção que organiza e racionaliza o uso de todos os recursos, tanto básicos como especializados, direcionados para a promoção, manutenção e melhora da saúde.

Outro aspecto importante levantado por diferentes autores relaciona-se à seletividade que caracteriza a atenção primária no cenário de crise econômica da década de 1980 e a emergência dos governos neoliberais nos países desenvolvidos, de onde derivam boa parte das agências que apóiam projetos de ajuda ao desenvolvimento de países pobres, o que colaborou para a disseminação de programas seletivos de atenção primária. 10

As políticas de ajuste estrutural e as idéias sobre reforma do Estado traziam como alvo a redução de gastos públicos, o que influenciou no arrefecimento das generosidades entre na- ções e na escolha de projetos de mais baixo custo e de curto prazo a serem financiados. A perpetuação da situação de crise econômica mundial nos anos 90 acirrou a tensão entre custo e qualidade dos sistemas de saúde. Muitos países encaminharam mudanças na condução de sua política, tornando-se a questão da eficiência e do bom desempenho dos sistemas de saúde a pedra de toque das reformas propostas.

Neste cenário, o "paradigma da economia da saúde”, baseado nos princípios da focalização e da seletividade, ganhou destaque na agenda dos organismos de cooperação internacional e passou a orientar a ação de instituições como o Banco Mundial, principal difusor dessas idéias.

O Banco Mundial defendia a idéia de "cestas básicas" de serviços de saúde, sugerindo que o setor público deveria prover um conjunto mínimo de ações essenciais aos que não pudessem arcar individualmente com os gastos em saúde. A cesta era composta tipicamente por ações classificadas como tecnologias simples e de alto impacto, como vacinação, pré-natal, ações de promoção e prevenção da saúde, ou seja, o mesmo conjunto de ações que compõem a atenção primária desde sua origem. As demais ações em saúde, especialmente aquelas de diagnóstico e terapia que implicam maior custo, deveriam ser ofertadas pelo setor privado ${ }^{11}$.

Embora se considere a diversidade de propostas para o setor de saúde entre os países, em termos gerais as reformas que vêm ocorrendo em muitos sistemas nacionais são motivadas por alguns pontos centrais: a questão dos custos da assistência médica, a busca por maior eficiência dos sistemas de saúde e a questão da descentralização das atividades e responsabilidades compartilhadas entre as esferas governamentais, o setor privado e os indivíduos. Estas reformas trazem alterações importantes na forma de alocação de recursos na área de assistência médica com vistas à redução dos gastos com atenção hospitalar, ao uso racional de recursos tecnológicos mais especializados e maior incremento das ações de promoção e prevenção ambulatorial, domiciliar e comunitária, tipicamente enfatizadas na atenção primária12.

Além da preocupação com os resultados em saúde, é importante dizer que o resgate da atenção primária se situa na atual questão de viabilidade dos sistemas de saúde. Os crescentes custos da atenção à saúde têm levado governos e instituições privadas que atuam no setor, tanto em países desenvolvidos ou em vias de desenvolvimento, a experimentar reformas em 
seus sistemas colocando a atenção primária como ponto central para melhorar a capacidade de resposta dos serviços de saúde, buscando prevenir os problemas de saúde ou tratá-los de maneira mais efetiva. O outro lado da moeda é a busca por melhores resultados na redução das internações hospitalares ou na redução do uso de procedimentos terapêuticos mais sofisticados, que implicam maior custo para o sistema de saúde13.

A atenção básica como componente estratégico da organização dos serviços de saúde dependerá, portanto, da capacidade de articulação dos recursos essenciais para o enfretamento de problemas de saúde em todos os seus níveis de complexidade. Nesta direção, uma outra lógica de construção do sistema de saúde precisa ser assumida de forma que possibilite maior flexibilidade das suas estruturas organizacionais em cada território e de um aporte tecnológico que se aproxime, o quanto for possível, das necessidades apresentadas pela população.

No Brasil, também, são apresentadas diferentes interpretações para a APS. Os cuidados primários de saúde, ao assumirem, na primeira metade da década de 1980, um caráter de programa de medicina simplificada para os pobres de áreas urbanas e rurais, em vez de uma estratégia de reorientação do sistema de serviços de saúde, acabou por afastar o tema do centro das discussões à época14.

Ainda hoje, persiste a acepção de programa focalizado, apesar da "superioridade conceitual da versão da Atenção Primária como estratégia de reformulação de todo o sistema de saúde"15. Pragmaticamente, pode-se adotar a conceituação de estratégia para o reordenamento do nível de atenção primária, com potencial de catalisar o reordenamento dos outros níveis.

O Ministério da Saúde brasileiro definiu a atenção básica, em 1999, como um conjunto de ações, de caráter individual ou coletivo, desenvolvidas no primeiro nível de atenção dos sistemas de serviços, voltadas para a promoção da saúde, prevenção dos agravos, tratamento e reabilitação. Na literatura analisada, como já foi referido, são escassas as pesquisas voltadas para avaliação organizacional ou de desempenho da $\mathrm{AB}$, e uma visão crítica dos mecanismos institucionais de monitoramento e avaliação da AB. Tanto o Pacto da Atenção Básica quanto o Sistema de Informação a Atenção Básica (Siab) não podem ainda ser considerados sistemas de avaliação de desempenho nem de monitoramento do conjunto de ações desenvolvidas em unidades de atenção básica, sejam elas referidas a equipes PSF ou não. Há necessidade de instrumentos ágeis e efetivos para uma avaliação organizacional e de desempenho da $\mathrm{AB}$ em nível local diante dos atuais instrumentos governamentais existentes.

A estratégia do estudo desenvolvido nos municípios de São Paulo a partir do projeto proposto pelo Ministério da Saúde foi utilizar para uma amostra dos municípios de São Paulo os mesmos instrumentos elaborados no trabalho já citado de Almeida et al. considerando as seguintes dimensões:

Acesso: envolve a localização da unidade de saúde próxima da população a qual atende, o horário e os dias em que está aberta para atender, e o grau de tolerância para consultas nãoagendadas.

Porta de entrada: implica acesso e uso do serviço a cada novo problema pelos quais as pessoas buscam atenção à saúde;

Vínculo (ou longitudinalidade): pressupõe a existência de uma fonte regular de atenção e seu uso ao longo do tempo. Assim a unidade de atenção primária deve ser capaz de identificar a população adscrita, bem como os indivíduos dessa população, que deveriam receber atendimento na unidade, exceto quando for necessário realizar uma consulta especializada ou fazer um encaminhamento. Além disso, o vínculo da população com a unidade de saúde deveria estar refletido em fortes laços interpessoais que refletissem a cooperação mútua entre as pessoas da comunidade e os profissionais de saúde;

Integralidade (ou elenco de serviços): implica que as unidades de atenção primária devem estabelecer arranjos para que o paciente receba todo tipo de serviço de atenção à saúde. Isto inclui o encaminhamento para consultas especializadas (nível secundário), serviços terciários, internação domiciliar e outros serviços comunitários;

Coordenação (ou integração dos serviços): pressupõe alguma forma de continuidade, seja por parte do atendimento pelo mesmo profissional, seja por meio de prontuários médicos, ou ambos, além do reconhecimento de problemas anteriores e novos e do encaminhamento e acompanhamento do atendimento em outros serviços especializados. Por exemplo, os problemas observados em consultas anteriores ou pelos quais houve algum encaminhamento para outros profissionais especializados deveriam ser avaliados nas consultas subseqüentes; 
Enfoque familiar: pressupõe a consideração do indivíduo em seu ambiente cotidiano, quando a avaliação das necessidades de saúde deve considerar o contexto familiar e a exposição a ameaças à saúde de qualquer ordem, além do enfrentamento do desafio dos recursos familiares limitados. Resulta do alcance da integralidade e da coordenação;

Orientação para a comunidade: implica o reconhecimento de que todas as necessidades de saúde da população ocorrem num contexto social determinado, que deve ser conhecido e tomado em consideração;

Formação profissional: pressupõe que a atenção básica seja uma área de "especialização" que requer formação específica. Requer que os profissionais de saúde sejam capacitados para desempenhar suas funções segundo as dimensões mencionadas anteriormente.

\section{Metodologia}

Fizeram parte do estudo os municípios localizados no Estado de São Paulo que possuem mais de 100 mil habitantes (total de 62), nos quais as estratégias de implantação do Programa Saúde da Família assumem características diferenciadas. O município de São Paulo, por possuir características muito diferentes e próprias com relação aos demais, foi analisado à parte e não integra o contexto desta pesquisa.

\section{Definição dos municípios}

A primeira etapa consistiu em definir categorias de municípios nas quais se pudesse classificá-los, de acordo com determinadas características e que permitissem compor grupos homogêneos. Nesta etapa foram considerados os 62 municípios que integram o campo de estudo da pesquisa.

Nessa categorização foram utilizados basicamente dois indicadores: o Índice de Responsabilidade Social (IPRS) do Estado de São Paulo e a complexidade da rede ambulatorial do município.

O IPRS é um indicador desenvolvido pela Fundação Seade por solicitação da Assembléia Legislativa do Estado de São Paulo.

Esse indicador preserva as três dimensões mais utilizadas na maioria dos indicadores de desenvolvimento humano - renda, escolaridade e longevidade. Além disso, procurou certas especificidades, a mais importante das quais a construção de uma tipologia de municípios que permitia identificar, simultaneamente, o estágio de desenvolvimento de um determinado município nas três dimensões consideradas. Esse tipo de indicador, apesar de não ser passível de ordenação, permite um maior detalhamento das condições de vida existentes no município. Pode-se verificar que $88 \%$ dos municípios se encontram nos grupos 1 e 2 do IPRS, que se caracterizam por apresentarem a riqueza municipal alta, e indicadores sociais (escolaridade e longevidade) bons no grupo 1 e mais desfavoráveis no grupo 2. Já que para a maioria dos municípios a dimensão riqueza não diferencia os municípios, definiu-se que os municípios seriam agrupados em duas categorias, considerando-se somente os indicadores sociais mais favoráveis e menos favoráveis. Para tanto, foram agregados os grupos 1 e 3 para formar a primeira categoria e os grupos 2, 4 e 5 , para formar a outra. A tabela 1 apresenta essa agregação.

A outra variável empregada para formação dos grupos de municípios foi a quantidade da produção ambulatorial do SUS apresentada por município para 2004 segundo grupo de produção, disponibilizada pelo Datasus. Os grupos de produção ambulatorial foram agregados segundo a complexidade dos procedimentos.

Para cada município, as porcentagens da produção ambulatorial em baixa, média e alta complexidade no total da produção desse município foram calculadas, desconsiderando-se os medicamentos e acompanhamentos de pacientes na alta complexidade. A partir desse conjunto de dados, foi feita uma análise de conglomerados com o objetivo de gerar três grupos homogêneos segundo as porcentagens de produção ambulatorial por complexidade. $\mathrm{O}$ resultado dessa análise permitiu classificar os municípios conforme a tabela 2.

A partir da combinação dos indicadores anteriormente descritos, foram elaborados os clusters da pesquisa (grupos homogêneos de municípios segundo algumas características anteriormente especificadas) assim denominados:

1. Baixa complexidade e Indicadores sociais menos favoráveis (15 municípios)

2. Média complexidade e Indicadores sociais menos favoráveis (12 municípios)

3. Alta complexidade e Indicadores sociais menos favoráveis (8 municípios)

4. Baixa complexidade e Indicadores sociais mais favoráveis (5 municípios) 
Tabela 1

Critérios para agrupar os municípios segundo o IPRS 2002.

\begin{tabular}{lccc}
\hline Grupos & $\begin{array}{c}\text { Grupos do } \\
\text { IPRS 2002 }\end{array}$ & No de municípios & \% de municípios \\
\hline Indicadores sociais menos favoráveis & 2 e 4 e 5 & 35 & \\
Indicadores sociais mais favoráveis & 1 e 3 & 27 & 56,5 \\
Total & & $\mathbf{6 2}$ & $\mathbf{1 0 0 , 0}$ \\
\hline
\end{tabular}

Fonte: Pesquisa Proesf, 2005.

\section{Tabela 2}

Critérios para classificação em grupos de municípios, segundo a porcentagem da produção apresentada por complexidade.

\begin{tabular}{llc}
\hline $\begin{array}{l}\text { Complexidade } \\
\text { do município }\end{array}$ & $\begin{array}{l}\text { Porcentagem da produção de baixa complexidade } \\
\text { no total da produção apresentada }\end{array}$ & No de municípios \\
\hline Baixa & maior que 63\% & 20 \\
Média & entre $50 \%$ e $63 \%$ & 21 \\
Alta & entre $20 \%$ e $50 \%$ & 21 \\
Total & & $\mathbf{6 2}$ \\
\hline
\end{tabular}

Fonte: Pesquisa Proesf, 2005.

1 Exclusive os medicamentos e acompanhamento a pacientes.

5. Média complexidade e Indicadores sociais mais favoráveis ( 9 municípios)

6. Alta complexidade e Indicadores sociais mais favoráveis (13 municípios)

Desta forma, os municípios escolhidos foram sorteados em cada estrato.

\section{Instrumentos utilizados}

O questionário utilizado para a avaliação dos usuários é uma adaptação dos instrumentos componentes do Primary Care Assessment Tool (PCAT), elaborado inicialmente na Universidade de John Hopkins ${ }^{8}$ e direcionado para a análise de aspectos relacionados à atenção primária em países industrializados e validado no Brasil em estudo realizado para a avaliação da rede básica do município de Petrópolis.

Existem quatro tipos de questionários para serem aplicados, de acordo com a avaliação que se pretende fazer: para os gestores da rede, para os profissionais que atuam nas unidades, para os usuários e para acompanhantes de usuários. Neste estudo, foram utilizados os três últimos, já que os gestores foram pesquisados em outro componente desta pesquisa. Desta forma, sua aplicação foi dirigida para colher dados para análise de dois universos: o dos trabalhadores de saúde que atuam nas UBS e o dos usuários dos serviços.

As estratégias de estudo adotadas foram:

1. Trabalhadores de saúde: foram entrevistados considerando-se dois estratos - os que compõem as equipes de Saúde da Família e os que atuam nas UBS tradicionais - com o intuito de comparar os resultados das avaliações dos trabalhadores entre os dois tipos de estratégias de atenção básica. O questionário é composto de 92 questões específicas sobre aspectos da atenção básica correspondentes aos indicadores de atenção básica mais utilizados.

2. Usuários de serviços: foram entrevistados os usuários e acompanhantes de serviços em todas as UBS, independentemente da estratégia de atenção, com o objetivo de avaliar os serviços prestados pela rede em geral. Os questionários para usuários contêm cerca de 100 perguntas, a maioria das quais usadas no questionário para profissionais. Há também algumas questões sobre demografia e saúde, abrindo-se a possibilidade de cotejar esses dados com aqueles oriundos da experiência do cliente no momento da atenção.

A cada entrevistado (usuário ou profissional) foram explicadas as diferentes opções de resposta, para que se identificasse a distância 
relativa entre cada resposta. Os entrevistadores explicaram aos entrevistados que cada resposta possuía um significado numérico (nunca $=0$; quase nunca $=1$; algumas vezes $=2$; muitas vezes $=$ 3; quase sempre $=4$; sempre $=5$ ) correspondendo ao número de vezes que, numa semana típi$\mathrm{ca}, \mathrm{o}$ evento perguntado teria acontecido.

\section{Seleção de entrevistados e tamanho da amostra}

Para a pesquisa com os trabalhadores das UBS foi estabelecido como critério de inclusão, para todos os médicos e enfermeiros, a atuação na unidade por pelo menos seis meses.

Nos dois questionários, o entrevistado responde a perguntas cujas respostas estavam estabelecidas em escala ordinal, à qual se atribuiu um valor entre zero e cinco. As respostas foram somadas e o valor médio das respostas de todas as perguntas para cada dimensão e o total foram calculados por pessoa entrevistada. Os dados para a análise desenvolvida foram as médias e intervalos de confiança calculados para os clusters e para as dimensões.

Para o universo de usuários, foram entrevistados aqueles que ao menos uma vez já tinham sido atendidos na UBS anteriormente, incluindo as três categorias de usuários para a pesquisa: adultos, adultos acompanhantes de crianças e adultos acompanhantes de deficientes para os quais foram utilizados questionários adaptados.

Quanto ao tamanho da amostra foram adotados dois planos. Para os trabalhadores foram entrevistados todos os médicos e enfermeiros que atuavam na unidade quando se tratava de UBS tradicional e apenas os médicos e enfermeiros das equipes da Saúde da Família nos outros casos. Foram escolhidas UBS sem equipes de Saúde da Família e com equipes de Saúde da Família, em acordo com a direção da Secretaria Municipal de Saúde, considerando-se como parâmetros de escolha: as unidades se situarem em áreas da cidade com situação socioeconômica semelhante; serem unidades consideradas de melhor padrão relativo de atendimento; e apresentarem a mais baixa rotatividade de servidores. Nas unidades onde só havia Saúde da Família, todos os médicos e enfermeiros das equipes foram entrevistados. Nas situações em que a unidade não era exclusiva para Saúde da Família (unidades mistas), foram entrevistados somente os médicos e enfermeiros que compõem as equipes de Saúde da Família.
Para os usuários foi desenvolvido um plano para a amostra com base em conglomerados, considerando um $\alpha$ de $5 \%$, um $\beta$ de $20 \%$ e o erro amostral de $10 \%$, através dos seguintes procedimentos:

1. O sorteio dos usuários foi realizado em duas etapas. Numa primeira, para os municípios mais populosos, sortearam-se UBs que comporiam a amostra. Para os demais, todas as UBS foram incluídas no estudo. Na segunda etapa, o número de usuários a ser entrevistado foi definido de acordo com a proporção de atendimentos do mês no posto. Através de uma lista feita no início do período de atendimento e que incluía todos aqueles que estivessem na unidade para prestação de algum de seus serviços e com uma planilha com uma tabela de números aleatórios a ser utilizada como base para o sorteio, os entrevistadores definiram os usuários a serem incluídos no estudo.

2. O número de usuários atendidos durante o mês de junho de 2005 serviu como base para o cálculo do volume de entrevistas a serem feitas em cada unidade. As entrevistas foram realizadas em dois períodos, pela manhã (das 8 às 12 horas) e à tarde (das 13 às 17 horas), preferentemente em dias diferentes da semana. $O$ fato de se obedecer à proporção de atendimentos para compor a amostra, tanto com relação à UBS, quanto também ao período, elimina a necessidade posterior de se considerar o peso relativo de cada unidade amostral e realizar as ponderações compensatórias para ajustar os resultados.

Quanto aos resultados, foram desenhados planos de análise diferentes para cada abordagem feita. $\mathrm{O}$ aplicativo utilizado para as análises estatísticas foi o SPSS 13.0. No que se refere aos profissionais, a principal comparação foi feita considerando os valores das dimensões e os totais encontrados no modelo PSF e no modelo tradicional intra-estrato e o teste estatístico utilizado foi não paramétrico de KruskallWallis \& Kish L16.

Para a análise dos usuários, calcularam-se as médias intra-estrato, as quais foram comparadas com as médias do estrato 6 para cada dimensão, pois este é o que apresenta os melhores indicadores do IPRS e de complexidade da rede. Para esta análise foi considerado o plano complexo de amostragem, utilizando-se a estatística Wald F para a verificação da significância estatística na comparação dos escores médios obtidos 17,18 . 


\section{Apresentação dos resultados}

A análise dos dados da pesquisa foi feita sob duas perspectivas distintas. Na primeira, considerando o fato de que tanto os usuários das unidades de saúde, quanto seus acompanhantes foram entrevistados com a finalidade de se avaliar o nível de satisfação da atenção básica, sem destaque para o PSF, as investigações se dirigiram principalmente para a obtenção dos escores médios alcançados em cada cluster e as comparações entre eles, de modo a indicar diferenças significativas no geral e em cada dimensão estudada. Na outra, a análise de satisfação dos profissionais atuantes na rede direcionou-se para as comparações entre aqueles que atuam em unidades tradicionais e nos que atuam em unidades com PSF, buscando apontar, dentro de cada cluster, as diferenças existentes ou não entre os escores médios em cada dimensão.

Há um aspecto importante a ressaltar que se refere ao fato de que, como o questionário está organizado em dimensões com quantidade diferente de perguntas, foi promovido um ajuste dos escores, relacionando os valores calculados com a máxima pontuação que poderia ser obtida em cada dimensão. Sendo assim, a apresentação das tabelas e gráficos e sua respectiva análise também são feitas em termos percentuais denominados de escores médios ajustados.

\section{Usuários e acompanhantes}

A amostra de usuários e acompanhantes foi analisada em conjunto, com intuito de avaliar o nível de satisfação relativa à atenção básica prestada pela rede de unidades públicas de saúde. Tendo como base os parâmetros apresenta- dos na metodologia, o número total de entrevistados foi de 2.923, proporcionalmente calculado pelo volume de atendimentos diários realizados pelos serviços municipais.

A tabela 3 apresenta uma descrição sumária das características gerais da amostra de usuários e acompanhantes.

A maioria dos entrevistados foi do sexo feminino, com média de idade de 45 anos para usuários e 32 anos para os acompanhantes, fato que somado ao grau de escolaridade (aproximadamente 1 a cada 4 usuários tem o primeiro grau completo e entre os acompanhantes isso só ocorre em $3 \%$ dos casos) infere uma situação social em que o papel feminino é nuclear no grupo familiar no cuidado à saúde. Em relação a bens de consumo, mais de $70 \%$ possuem telefone (fixo ou móvel) e só um terço tem carro. Tais números refletem o grande acesso que têm a esses bens mesmo as populações situadas na periferia econômica e social do sistema. Quanto aos serviços públicos básicos, mais de 95\% dos entrevistados, nos dois grupos, tinham acesso à água encanada, coleta de esgoto e de lixo, assim como, na mesma proporção, possuíam banheiro dentro do domicílio, um resultado esperado em função do porte dos municípios estudados.

Como já foi mencionado na metodologia, a análise das respostas dadas pelos usuários e acompanhantes foi elaborada calculando-se as médias e intervalos de confiança para cada cluster fazendo as comparações entre clusters, tomando como referência o cluster 6 . Para a obtenção das estatísticas, as entrevistas dos usuários e dos acompanhantes dos municípios componentes de cada cluster foram agregadas.

Os valores dos escores médios e os respectivos intervalos de confiança foram calculados e estão apresentados nos gráficos 1 e 2 .

Tabela 3

Características gerais da amostra dos usuários e acompanhantes segundo sexo, idade, escolaridade e bens de consumo. Estado de São Paulo, 2005.

\begin{tabular}{llcc}
\hline Característica & Índice & Usuários & Acompanhantes \\
\hline Sexo & Feminino & $73,6 \%$ & $51,2 \%$ \\
Idade (anos) & Média & 45,6 & 32,3 \\
& Desvio-padrão & 16,8 & 10,7 \\
Escolaridade & 1o grau completo ou mais & $28,8 \%$ & $3,0 \%$ \\
Telefone & Sim & $78,8 \%$ & $71,2 \%$ \\
Carro & Sim & $35,6 \%$ & $33,8 \%$ \\
\hline
\end{tabular}

Fonte: Pesquisa Proesf, 2005. 


\section{Gráfico 1}

Escores médios totais por cluster, Estado de São Paulo, 2005.

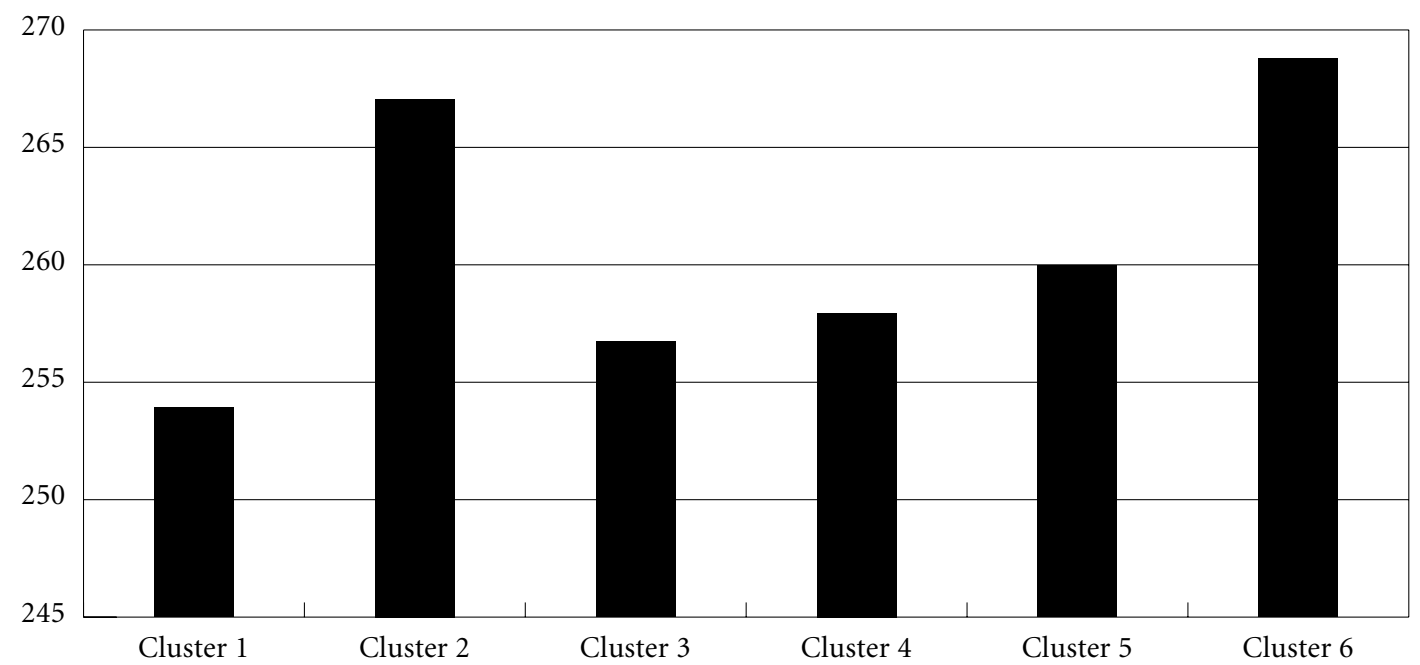

\section{Gráfico 2}

Escores médios totais ajustados por cluster, Estado de São Paulo, 2005.

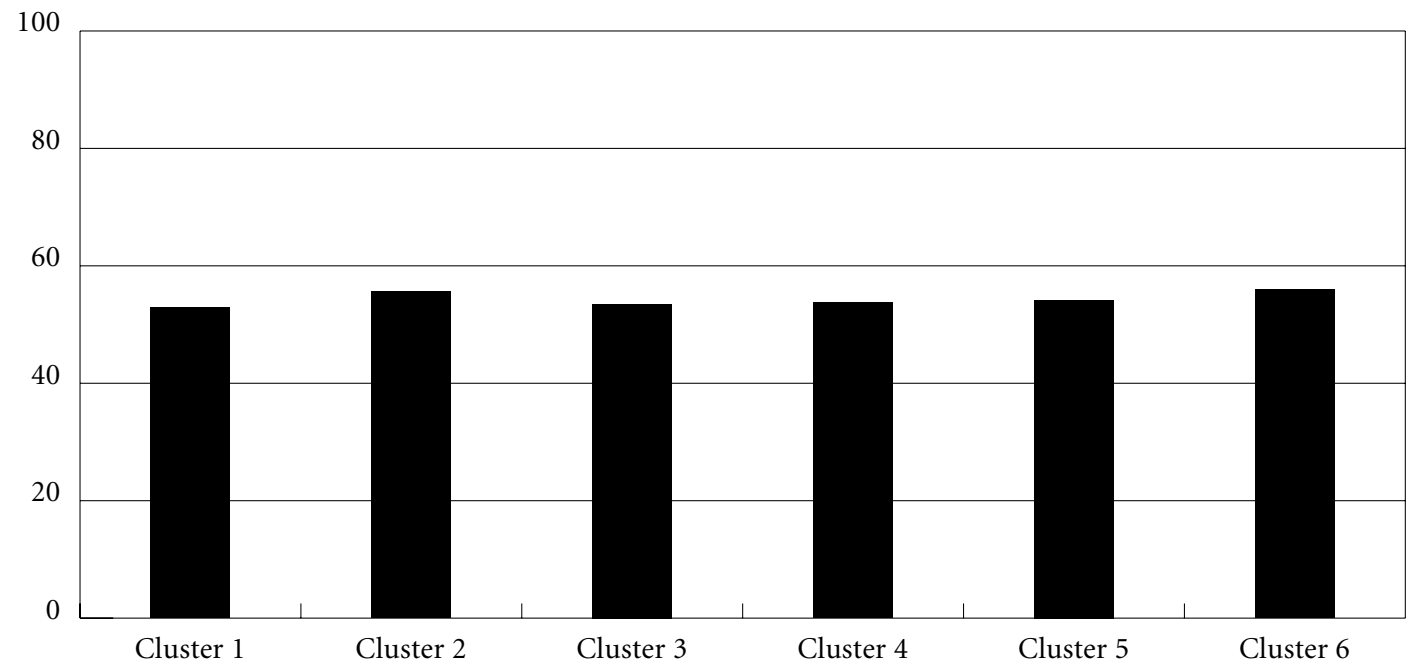


Observa-se que há uma tendência de aumento dos valores médios, mesmo que em pequena escala, relacionado à escala de melhor qualificação do cluster, com exceção do cluster 2. Todavia, os valores obtidos em relação aos escores ajustados mostram que a proporção das pontuações médias está próxima de $50 \%$, o que se pode considerar um nível de satisfação intermediário para todos os clusters em relação ao potencial de alcance dos escores.

Os mesmos cálculos foram feitos para cada dimensão do estudo envolvendo os 11 municípios, com a intenção de avaliar os escores simples e ajustados obtidos.

A tabela 4 revela os valores médios e intervalos de confiança por dimensão. Nos escores simples observa-se que há pouca variação dos valores em cada dimensão, já que os intervalos são pequenos. Quando se dirige a análise para os escores ajustados, aparecem quais as dimensões que alcançaram os melhores percentuais de satisfação. A Porta de entrada, que enfoca a capacidade da unidade em dar resposta a novas demandas ou recorrências, o Vínculo, que se refere à condição da unidade em ser uma fonte regular de atenção, e Profissionais de saúde, que trata da relação direta dos usuários e acompanhantes com os profissionais de saúde, apresentam os melhores percentuais. O Enfoque familiar, que trata do contexto de vida dos usuários, e a Orientação comunitária, a Coordenação e a Acessibilidade, que envolve o interesse dos serviços pelos problemas coletivos da comunidade usuária, tiveram os menores percentuais. De certa forma, numa análise mais global, as dimensões que envolvem a atenção direta na unidade de saúde são mais bem avaliadas do que as outras cuja essência requer mudanças mais profundas na cultura e comportamento dos serviços. Convém lembrar que, com algumas exceções, os municípios participantes do estudo possuem baixos percentuais de cobertura do PSF e têm seu modelo de atenção básica baseado em unidades tradicionais de atendimento.

De modo geral, as médias ajustadas dos escores têm percentuais mais elevados nos clusters mais bem qualificados, o que ratifica de certa forma a melhor condição dos municípios mais desenvolvidos em prestar serviços de saúde. No entanto, isso não acontece em duas dimensões: no Elenco de serviços, que considera a integralidade da atenção prestada, e na Orientação comunitária, na qual os valores assumem uma variação inversa aos demais. Uma inferência possível, uma vez que os clusters com indicadores sociais mais favoráveis e com diferentes gradações de complexidade da rede tenham à disposição outros tipos de serviço suplementares que acabem conformando serviços menos preocupados com essas duas dimensões. $\mathrm{Ou}$ ainda que os municípios menos desenvolvidos se preocupariam relativamente mais com ações e atividades externas com algum caráter coletivo. Isso mereceria uma análise mais aprofundada, já que os escores ajustados apresentam variações pequenas e os detalhes a respeito das formas de prestação são bastante numerosos.

Os gráficos de 3 a 10 ilustram as mesmas tendências dos clusters por dimensão separadamente.

A análise estatística das diferenças dos escores médios simples de cada dimensão foi feita comparando-se cada um dos clusters com o

\begin{tabular}{|c|c|c|c|c|c|c|}
\hline \multirow[t]{2}{*}{ Dimensões } & \multicolumn{3}{|c|}{ Valores simples } & \multicolumn{3}{|c|}{ Valores ajustados (\%) } \\
\hline & Média & inferior & superior & Média & inferior & superior \\
\hline Acessibilidade & 30,71 & 30,08 & 31,35 & 46,5 & 45,6 & 47,5 \\
\hline Porta de entrada & 15,41 & 15,13 & 15,69 & 85,6 & 84,1 & 87,2 \\
\hline Vínculo & 45,69 & 45,11 & 46,28 & 76,2 & 75,2 & 77,1 \\
\hline Elenco de serviços & 74,17 & 72,46 & 75,88 & 56,2 & 54,9 & 57,5 \\
\hline Coordenação & 44,71 & 43,34 & 46,07 & 41,4 & 42,5 & 45,2 \\
\hline Enfoque familiar & 12,58 & 12,07 & 13,09 & 41,9 & 40,2 & 43,6 \\
\hline Orientação comunitária & 11,72 & 11,01 & 12,43 & 32,6 & 30,6 & 34,5 \\
\hline Profissionais de saúde & 26,64 & 26,22 & 27,06 & 74,0 & 72,8 & 75,2 \\
\hline Total & 261,63 & 255,42 & 267,83 & 53,8 & 53,0 & 55,3 \\
\hline
\end{tabular}

Fonte: Pesquisa Proesf, 2005. 


\section{Gráfico 3}

Médias e intervalos de confiança ajustadas para Acessibilidade por cluster.

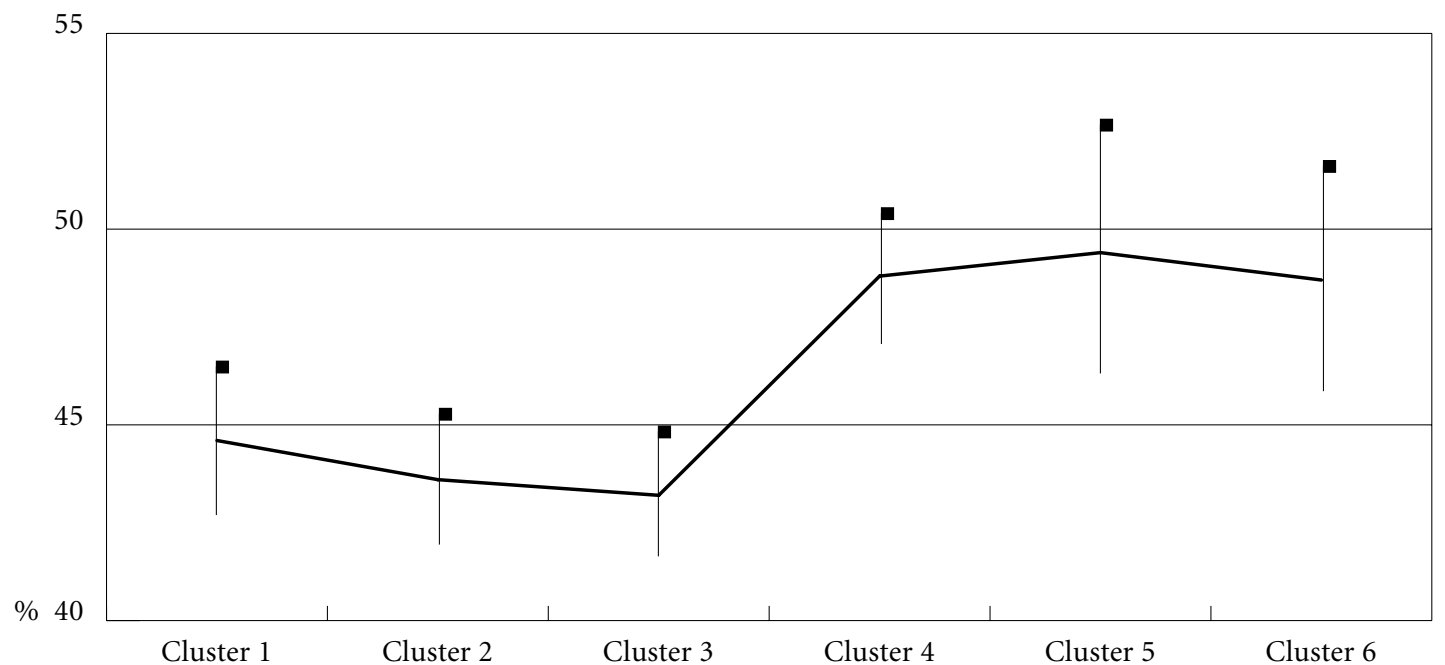

\section{Gráfico 4}

Médias e intervalo de confiança ajustados para Porta de Entrada por cluster.

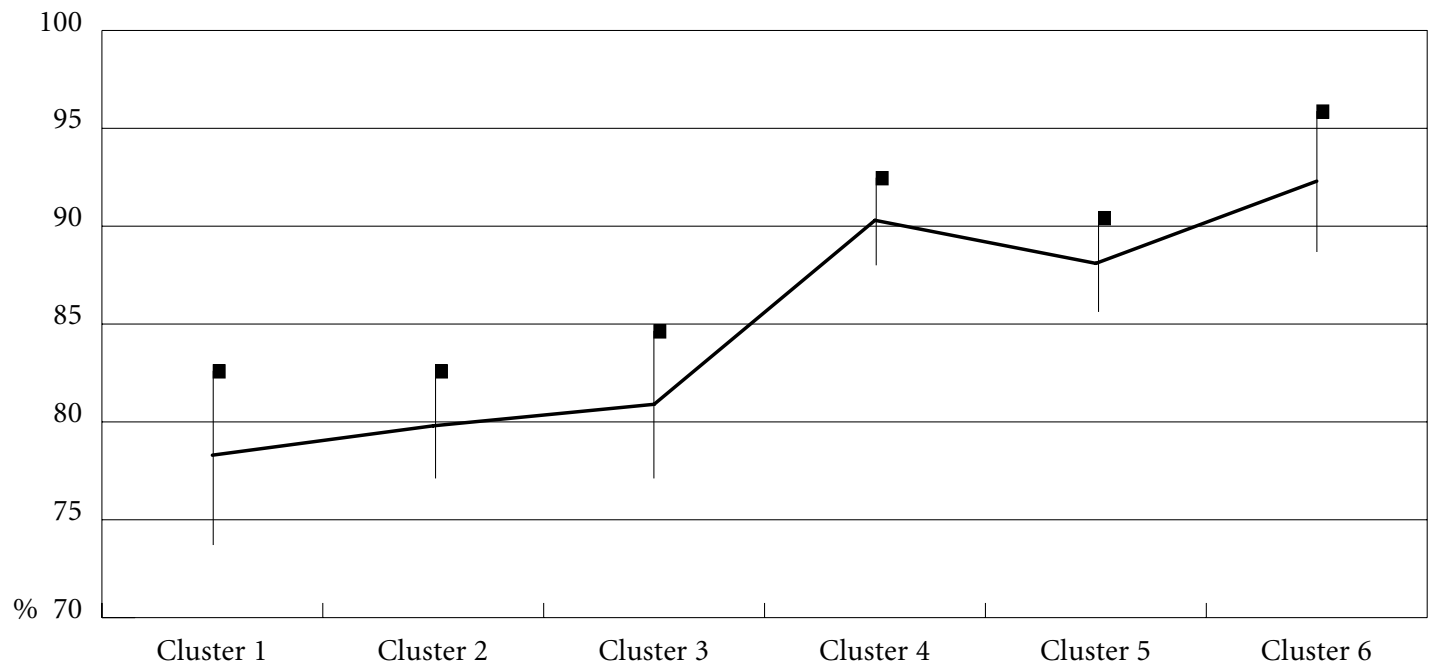




\section{Gráfico 5}

Médias e intervalo de confiança ajustados para Vínculo por cluster.

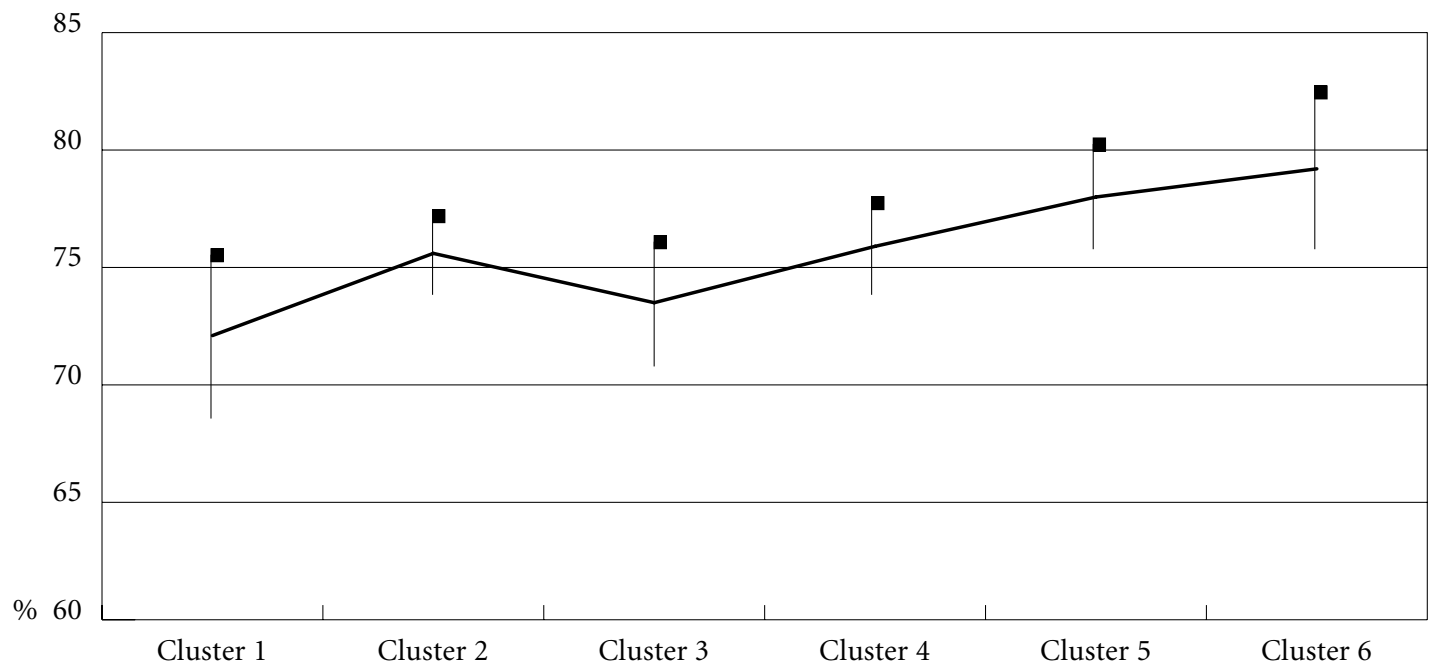

\section{Gráfico 6}

Médias e intervalos de confiança ajustados para Elenco de Serviços por cluster.

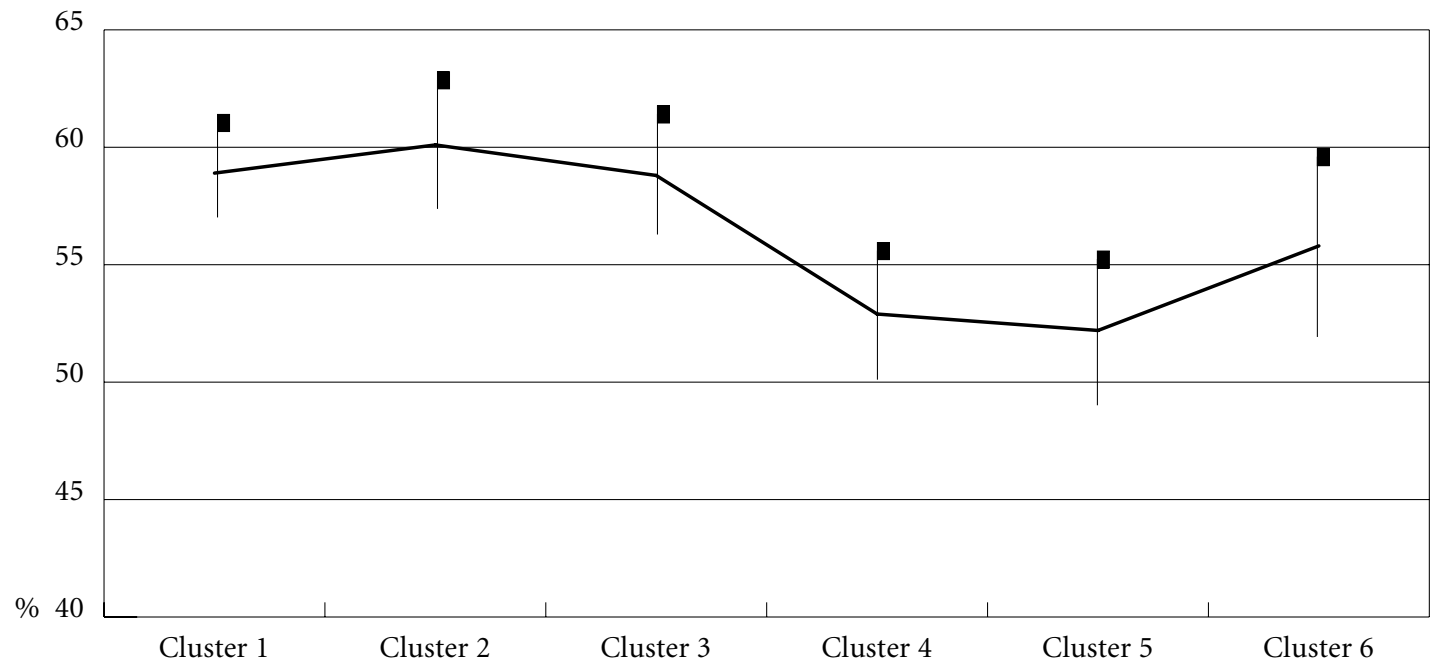




\section{Gráfico 7}

Médias e intervalos de confiança ajustados para Coordenação por cluster.

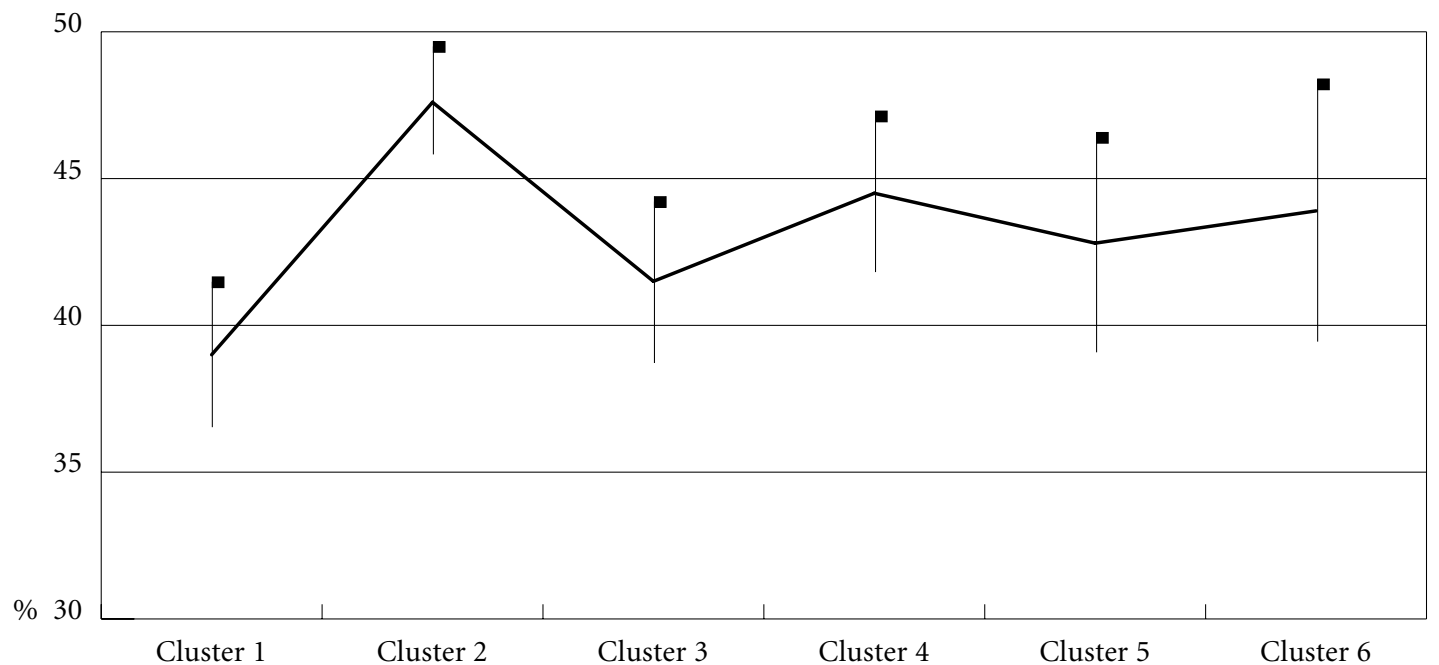

\section{Gráfico 8}

Médias e intervalos de confiança ajustados para Enfoque Familiar por cluster.

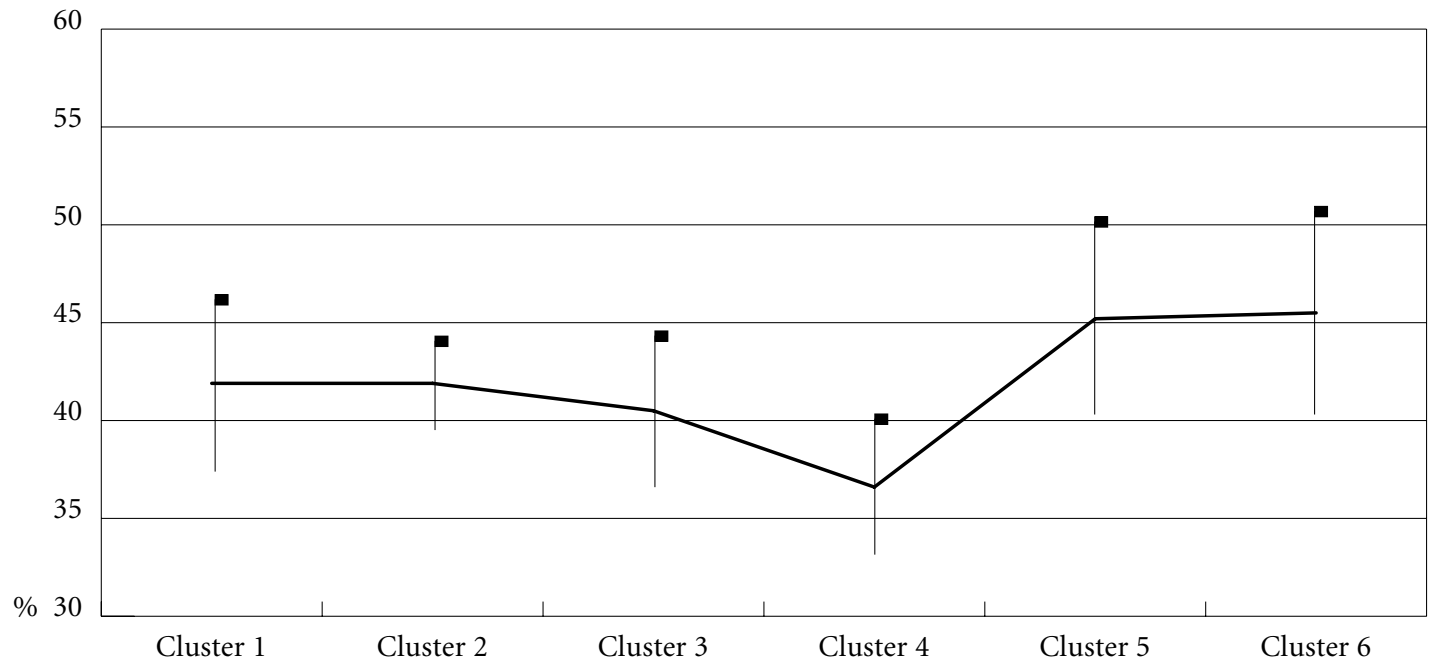




\section{Gráfico 9}

Médias e intervalos de confiança ajustados para Orientação Comunitária por cluster.

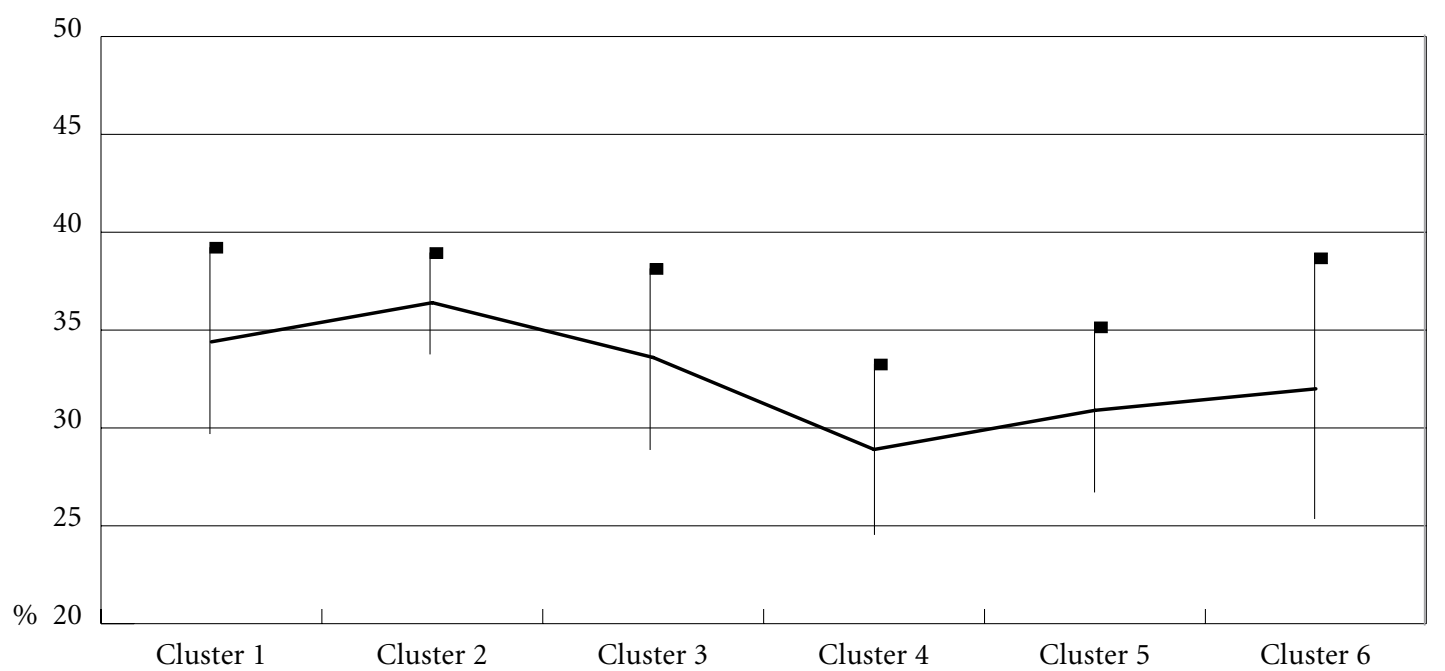

\section{Gráfico 10}

Médias e intervalos de confiança ajustados para Profissionais de Saúde por cluster.

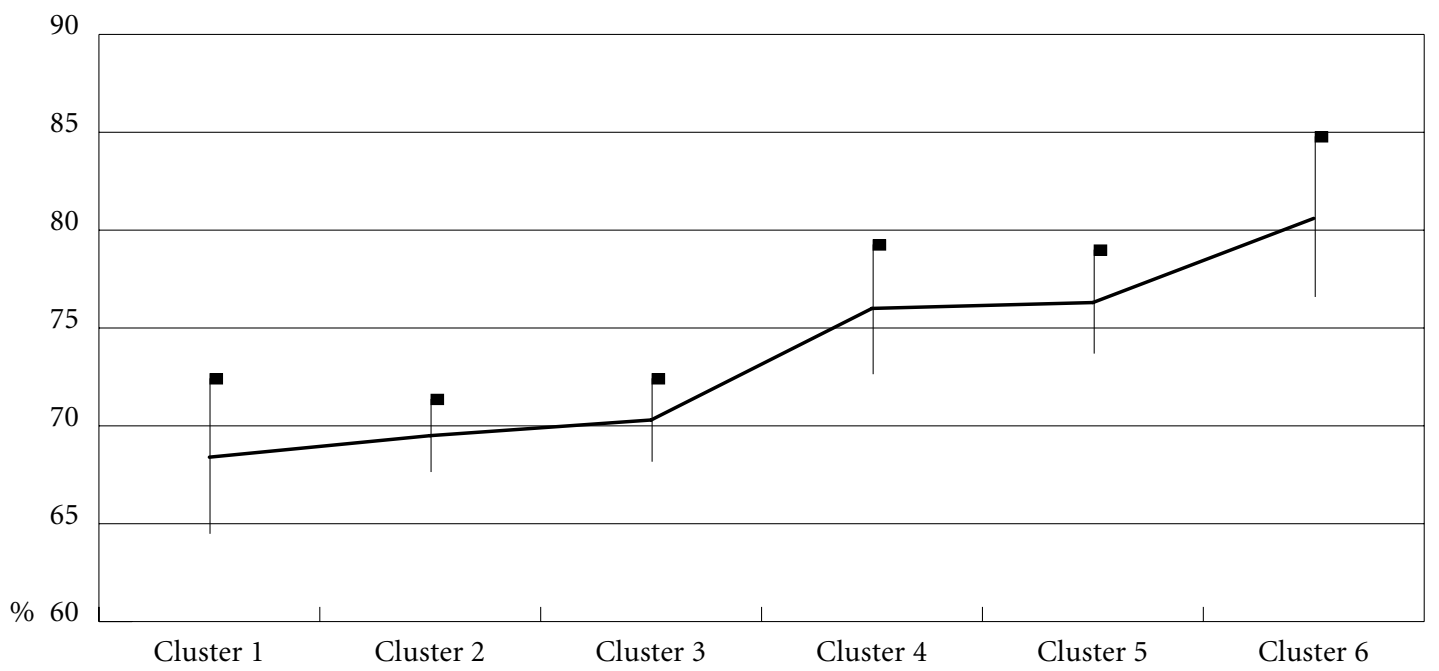


cluster 6 . Os resultados dos testes estão resumidos na tabela 5 .

De início, ao analisar os totais dos escores médios por cluster, não há diferença significativa em nenhuma das combinações em relação ao cluster 6, o que já havia de certa forma aludido no início dos resultados já que a diferença numérica entre os escores foi pequena.

Quanto às comparações considerando as dimensões há certo padrão de diferenças encontradas, pois nos clusters 1, 2 e 3, para Acessibilidade, Porta de entrada e Profissionais de saúde ocorre diferença significativa entre os escores médios simples. O mesmo se repete para Vínculo, com exceção do cluster 3. Para os municípios menos qualificados pode-se dizer que há menor satisfação dos usuários quanto à localização, facilidade de atendimento, regularidade e com o trato dos profissionais de saúde. Podem-se reiterar afirmações anteriores de que o nível de satisfação é menor quando se aborda a atenção prestada exclusivamente na unidade de saúde. Como o conjunto dos municípios que compõem esses clusters é quase todo da região da Grande São Paulo é fundamental considerar o processo e a realidade metropolitana como importante fator condicionante na satisfação dos usuários dos serviços.

Há diferença significativa na comparação do cluster 4 no que se refere ao enfoque familiar, que poderia ser atribuído a um baixo escore médio alcançado por um dos municípios componentes do cluster e que mereceria um estudo mais detalhado.

Para as demais comparações tomando as outras dimensões, apesar de não haver diferença significativa entre os clusters no modelo pro- posto, é importante ressaltar que os valores médios ajustados dos escores giram ao redor de $50 \%$, o que pode ser considerado um padrão baixo do nível de satisfação dos usuários em relação à atenção básica desses municípios.

\section{Trabalhadores em saúde}

A tabela 6 apresenta a amostra final de profissionais entrevistados pela pesquisa. O número de entrevistados variou em função dos critérios de amostragem que levou em consideração tanto a cobertura de PSF no município, a qual no geral era baixa, quanto a comparabilidade das regiões dos dois tipos de unidades básicas amostradas, PSF e tradicional. Além disso, em determinados clusters houve uma grande dificuldade de acessar estes profissionais. Assim, o número de profissionais entrevistados nos clusters 4, 5 e 6 foi pequeno, 13, 15 e 9 entrevistas, respectivamente, o que implica um baixo poder para os testes de significância estatística aplicados nestas análises. Em outras palavras, a não detecção de diferenças estatísticas pode apenas refletir o pequeno tamanho da amostra para estes clusters.

Estes profissionais estavam em média exercendo a função há doze anos, o que indica uma razoável experiência. A grande maioria dos entrevistados era de médicos (64\%), seguido por enfermeiros (19\%), prevalecendo, também, o sexo feminino $(63 \%)$.

A análise da qualidade da atenção primária segundo profissionais privilegiou a comparação PSF-UBS tradicional dentro de cada dimensão e cluster de municípios. As tabelas 7 e 8 detalham estas comparações.

\section{Tabela 5}

Valores de $P$ para estatística Wald na comparação dos valores médios por dimensão entre os clusters, tomando como referência o cluster 6. Estado de São Paulo, 2005.

\begin{tabular}{lcccccc}
\hline Dimensões/Cluster & $\mathbf{1}$ & $\mathbf{2}$ & $\mathbf{3}$ & $\mathbf{4}$ & $\mathbf{5}$ & $\mathbf{6}$ \\
\hline Acessibilidade & 0,015 & 0,002 & 0,001 & 0,988 & 0,742 & Referência \\
Porta de entrada & 0,000 & 0,000 & 0,000 & 0,351 & 0,063 & Referência \\
Vínculo & 0,004 & 0,064 & 0,010 & 0,100 & 0,581 & Referência \\
Elenco de serviços & 0,153 & 0,067 & 0,193 & 0,247 & 0,153 & Referência \\
Coordenação & 0,060 & 0,122 & 0,371 & 0,800 & 0,704 & Referência \\
Enfoque familiar & 0,287 & 0,202 & 0,131 & 0,005 & 0,947 & Referência \\
Orientação comunitária & 0,566 & 0,231 & 0,708 & 0,431 & 0,770 & Referência \\
Profissionais de saúde & 0,000 & 0,000 & 0,000 & 0,080 & 0,075 & Referência \\
Total & $\mathbf{0 , 1 3 2}$ & $\mathbf{0 , 9 4 4}$ & $\mathbf{0 , 1 8 1}$ & $\mathbf{0 , 1 7 8}$ & $\mathbf{0 , 2 8 0}$ & Referência \\
\hline
\end{tabular}

Fonte: Pesquisa Proesf, 2005. 


\section{Tabela 6}

Amostra de profissionais de saúde, por cluster.

Estado de São Paulo, 2005.

\begin{tabular}{lcc}
\hline Cluster & \multicolumn{2}{c}{ Profissionais de saúde } \\
& $\mathrm{n}$ & $\%$ \\
\hline 1 & 53 & 31,8 \\
2 & 28 & 16,8 \\
3 & 49 & 29,3 \\
4 & 13 & 7,8 \\
5 & 15 & 9,0 \\
6 & 9 & 5,4 \\
Total & $\mathbf{1 6 7}$ & $\mathbf{1 0 0 , 0}$ \\
\hline
\end{tabular}

Fonte: Pesquisa Proesf, 2005.

De um modo geral, os dados demonstram que os profissionais que trabalham no PSF avaliam o seu desempenho como sendo melhor, o que se reflete em escores médios maiores. Além disso, sempre que houve diferença estatística entre os dois tipos de unidade, esta foi favorá-

As diferenças entre PSF e unidade tradicional foram mais evidentes nos clusters 1, 2 e 3, com cinco e seis dimensões apresentando diferenças estatisticamente significantes. Os clusters 4 e 5 apresentaram ambos diferenças apenas em duas dimensões. Ao passo que no cluster 6 nenhuma diferença estatisticamente significante foi detectada. Mais uma vez cabe lembrar o menor poder dos testes estatísticos nos clusters com menor número de entrevistados, não sendo, assim, adequado especificar as diferenças internas a estes clusters. Desta forma, os

\section{Tabela 7}

Escore médio por dimensão, cluster e tipo de unidade (PSF/UBS), profissionais de saúde. Estado de São Paulo, 2005.

\begin{tabular}{|c|c|c|c|c|c|c|c|c|c|c|c|c|}
\hline \multirow[t]{2}{*}{ Dimensões } & \multicolumn{2}{|c|}{ Cluster 1} & \multicolumn{2}{|c|}{ Cluster 2} & \multicolumn{2}{|c|}{ Cluster 3} & \multicolumn{2}{|c|}{ Cluster 4} & \multicolumn{2}{|c|}{ Cluster 5} & \multicolumn{2}{|c|}{ Cluster 6} \\
\hline & PSF & UBS & PSF & UBS & PSF & UBS & PSF & UBS & PSF & UBS & PSF & UBS \\
\hline Acessibilidade & 26,0 & 26,8 & 25,3 & 24,7 & 25,9 & 24,9 & 29,7 & 31,6 & 27,0 & 29,0 & 22,5 & 19,9 \\
\hline Porta de entrada & 5,9 & 5,6 & 5,9 & 5,8 & 5,7 & 5,4 & 6,0 & 5,7 & 5,8 & 6,0 & 6,0 & 4,4 \\
\hline Vínculo & $38,4^{\star}$ & 29,6 & $39,4^{*}$ & 33,2 & $35,7^{*}$ & 32,7 & $40,5^{\star}$ & 31,6 & 41,8 & 39,3 & 40,5 & 31,0 \\
\hline Elenco de serviços & $126,1^{\star}$ & 103,3 & $120,9^{*}$ & 94,5 & $124,8^{*}$ & 96,6 & 131,2 & 129,9 & $132,0^{*}$ & 103,7 & 128,5 & 94,9 \\
\hline Coordenação & $98,6^{*}$ & 84,7 & 96,9 & 87,5 & 93,6 & 86,8 & 97,3 & 88,1 & 102,2 & 97,3 & 98,0 & 78,1 \\
\hline Enfoque familiar & $21,4^{*}$ & 15,3 & $22,0^{*}$ & 15,6 & $20,9^{*}$ & 15,3 & $22,8^{*}$ & 15,7 & $24,0^{*}$ & 18,3 & 24,0 & 16,1 \\
\hline Orientação comunitária & $32,8^{*}$ & 20,6 & $31,4^{*}$ & 16,1 & $31,7^{*}$ & 15,8 & 35,3 & 25,6 & $39,3^{*}$ & 21,7 & 31,0 & 18,9 \\
\hline Profissionais de saúde & $23,0^{*}$ & 16,6 & 23,7 & 18,6 & $22,6^{*}$ & 16,1 & 23,0 & 18,9 & 24,3 & 22,0 & 22,5 & 21,3 \\
\hline Auto-avaliação de confiança & 9,6 & 8,4 & $11,3^{*}$ & 8,6 & $10,3^{*}$ & 8,2 & 7,7 & 10,1 & 11,8 & 10,7 & 12,0 & 8,3 \\
\hline Total & 381,8 & 310,9 & 376,8 & 304,6 & 371,2 & 301,8 & 393,5 & 357,2 & 408,2 & 348,0 & 385,0 & 292,9 \\
\hline
\end{tabular}

Fonte: Pesquisa Proesf, $2005\left({ }^{*} \mathrm{p}<0,05\right)$. clusters 4, 5 e 6 serão discutidos apenas em relação às tendências gerais de PSF/UBS.

Em nenhum cluster houve diferença entre PSF e UBS tradicional nas dimensões de acessibilidade e porta de entrada, sendo que estas apresentam as menores diferenças relativas.

Por outro lado, as dimensões relativas ao vínculo, ao elenco de serviços, ao enfoque familiar e à orientação comunitária foram consistentemente mais bem avaliadas pelos profissionais de unidades PSF nos clusters 1, 2 e 3.

No cluster 1 as diferenças favoráveis ao PSF (maiores escores) ocorreram nas seguintes dimensões: vínculo, elenco de serviços, coordenação, enfoque familiar, orientação comunitária e profissionais de saúde.

No cluster 2 o desempenho das unidades de PSF também foi mais bem avaliado em relação ao vínculo, elenco de serviços, enfoque familiar e orientação comunitária. Não houve diferença, no entanto, na dimensão relativa aos profissionais de saúde.

O cluster 3 apresentou um comportamento semelhante ao cluster 1 em relação à melhor avaliação dos profissionais das unidades de PSF, em relação ao vínculo, ao elenco de serviços, ao enfoque familiar, orientação comunitária e profissionais de saúde. Não houve diferença estatisticamente significante em relação à dimensão que avalia a coordenação dos serviços.

Ressalte-se ainda que, quanto às questões relativas à auto-avaliação de confiança nas respostas (as respostas basearam-se em informações com consulta de dados e relatórios e se não qual o grau de segurança que teriam essas informa- 
Tabela 8

Diferença relativa do escore médio entre tipo de unidade (PSF/UBS), dimensão e cluster, profissionais de saúde. Estado de São Paulo, 2005.

\begin{tabular}{lcccccc}
\hline Dimensão & Cluster 1 & Cluster 2 & Cluster 3 & Cluster 4 & Cluster 5 & Cluster 6 \\
\hline Acessibilidade & $-0,8$ & 0,6 & 1,0 & $-1,9$ & $-2,0$ & 2,6 \\
Porta de entrada & 0,3 & 0,1 & 0,3 & 0,3 & $-0,2$ & 1,6 \\
Vínculo & 8,8 & 6,2 & 3,0 & 8,9 & 2,5 & 9,5 \\
Elenco de serviços & 22,8 & 26,4 & 28,2 & 1,3 & 28,3 & 33,6 \\
Coordenação & 13,9 & 9,4 & 6,8 & 9,2 & 4,9 & 19,9 \\
Enfoque familiar & 6,1 & 6,4 & 5,6 & 7,1 & 5,7 & 7,9 \\
Orientação comunitária & 12,2 & 15,3 & 15,9 & 9,7 & 17,6 & 12,1 \\
Profissionais de saúde & 6,4 & 5,1 & 6,5 & 4,1 & 2,3 & 1,2 \\
Auto-avaliação de confiança & 1,2 & 2,7 & 2,1 & $-2,4$ & 1,1 & 3,7 \\
Total & $\mathbf{7 0 , 8}$ & $\mathbf{7 2 , 2}$ & $\mathbf{6 9 , 4}$ & $\mathbf{3 8 , 5}$ & $\mathbf{6 0 , 0}$ & $\mathbf{9 2 , 1}$ \\
\hline
\end{tabular}

Fonte: Pesquisa Proesf, 2005.

ções) feita pelos profissionais entrevistados, apenas os clusters 2 e 3 apresentaram diferenças estatisticamente significantes. Em ambos, os profissionais do PSF tiveram melhor avaliação, embora a diferença relativa seja pequena.

\section{Profissionais versus usuários}

A avaliação dos serviços pelos profissionais mostrou-se, desta forma, um pouco distinta daquela feita pelos usuários. Estas diferenças tornam-se mais evidentes quando são comparados os escores médios ajustados por dimensão, o que pode ser avaliado no gráfico 11 .

De um modo geral, as avaliações são coincidentes para acessibilidade, porta de entrada e vínculo.

A acessibilidade foi avaliada de forma semelhante tanto pelos profissionais, quanto pelos usuários ficando num patamar apenas razoável segundo o máximo de pontos possíveis do instrumento para esta dimensão, isto é, aproximadamente $50 \%$ do total.

A porta de entrada é uma das dimensões com melhor avaliação seja pelos profissionais, seja pelos usuários. Em ambos, ela se situa acima dos $80 \%$ do valor total.

A dimensão relativa ao vínculo também tende a ser bem avaliada por profissionais e usuários.

Pode-se dizer que a dimensão de elenco de serviços é bem avaliada pelos profissionais de saúde, quase $80 \%$, e razoavelmente pelos usuários, quase $60 \%$.

Coordenação e enfoque familiar apresentam diferença ainda maior entre usuários e profissionais, com profissionais avaliando estas di- mensões muito bem (por volta do $80 \%$ ), ao passo que usuários avaliam que estas dimensões são apenas $40 \%$ do total de pontos possíveis.

A orientação comunitária é também mais bem avaliada pelos profissionais, embora seja apenas razoável para estes $(60 \%)$ e ruim para os usuários (40\%).

Por fim, a dimensão relativa aos profissionais de saúde é a única que, de forma consistente, é mais bem avaliada pelos usuários do que pelos profissionais entrevistados, sendo que em ambos atingem patamares relativos apenas razoáveis.

\section{Considerações finais}

Como considerações finais deste artigo, e que representam as primeiras tendências identificadas nos resultados obtidos na pesquisa, apresentaremos um resumo dos principais resultados encontrados. Teceremos depois alguns comentários que julgamos pertinentes à avaliação da organização e desempenho a partir da percepção de usuários e profissionais.

\section{Resumo dos principais resultados encontrados}

Para a avaliação da Atenção Básica pelos Usuários e Acompanhantes:

- como resultado geral, não há diferença no nível de satisfação entre os clusters estudados, ficando em $50 \%$ em média a percepção dos usuários quanto à atenção básica dos municípios estudados, o que de certa forma a qualifica como pouco satisfatória; 


\section{Gráfico 11}

Escores médios ajustados por dimensões e tipo de informante, 2005.

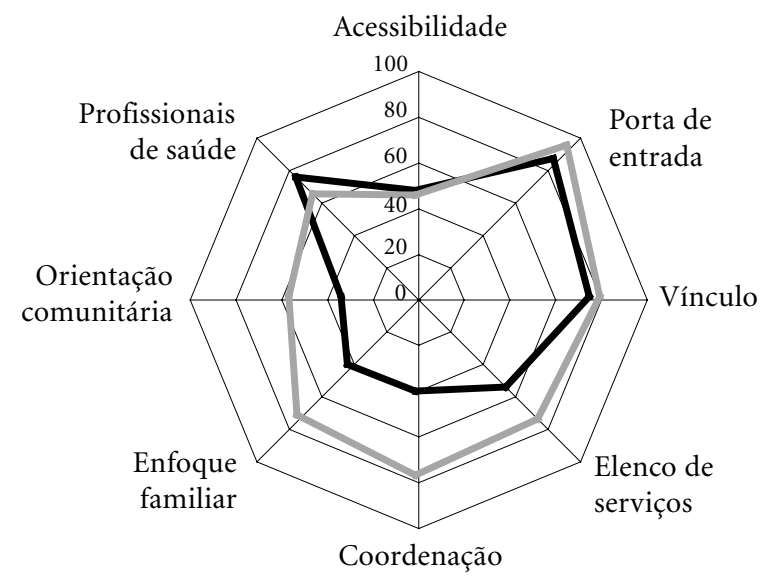

Usuários

Profissionais
- há maior cumprimento dos postulados da Atenção básica nos clusters com indicadores sociais mais favoráveis em todas as dimensões estudadas com exceção de Elenco de serviços e Orientação comunitária;

- os valores dos escores relativos, com exceção de Porta de entrada, Vínculo e Profissionais de saúde giram ao redor de $50 \%$ ou menos, o que indica uma avaliação de intermediária para ruim da prestação de serviços;

- a comparação dos escores médios dos clusters em relação ao cluster 6 por dimensão mostrou que ocorre diferença significativa nos clusters 1,2 e 3 para Acessibilidade, Porta de entrada e Profissionais de saúde.

Para avaliação da atenção tradicional e PSF pelos trabalhadores da saúde:

- os profissionais que trabalham no PSF avaliam o desempenho como sendo melhor do que julgam aqueles que trabalham em unidades tradicionais;

- as dimensões relativas à Acessibilidade e à Porta de entrada mostraram-se semelhantes tanto para os profissionais de PSF quanto de unidades tradicionais;

- os clusters 1, 2 e 3 permitem evidenciar de forma consistente que as dimensões Vínculo, Elenco de serviços, Enfoque familiar e Orientação comunitária foram mais bem avaliadas pelos profissionais do PSF;
- usuários e profissionais têm opiniões semelhantes apenas em relação às dimensões de Acessibilidade, Porta de entrada e Vínculo;

- profissionais tendem a avaliar melhor que os usuários todas as dimensões, exceto a dimensão relativa aos profissionais de saúde.

A primeira consideração de ordem mais geral aos resultados encontrados diz respeito ao agrupamento desses municípios pelos clusters divididos nos grupos de indicadores menos e mais favoráveis. Com algumas exceções, o primeiro grupo concentra os municípios pertencentes às regiões metropolitanas do Estado, onde o processo de modernização incompleta tem raiz numa migração de populações mais pobres para áreas menos valorizadas, e, por isso mesmo, carentes de infra-estruturas e serviços urbanos essenciais 19, 20. A dinâmica territorial paulista auxilia na explicação da concentração desses municípios com mais de 100 mil habitantes nas proximidades das regiões metropolitanas e com indicadores sociais que constatam a precariedade das condições de vida de parte da população que aí reside. No caso específico da região metropolitana de São Paulo, um documento elaborado por técnico da Secretaria Estadual no final da década de 1970 já colocava claramente a desigualdade entre esta região e o interior do Estado quanto à rede básica de serviços, propondo a construção de mais de 400 unidades básicas de saúde e 40 hospitais gerais para essa região. Esse estudo serviu de base para a instituição do Programa Metropolitano de Saúde na década de 1980, parceria do Governo estadual e o Banco Internacional de Reconstrução e Desenvolvimento (Bird) resultando num forte investimento com a construção de 100 Unidades Básicas de Saúde e cinco hospitais, a definição de um novo modelo assistencial centrado na atenção básica e uma reforma estrutural da secretaria redefinindo suas estruturas regionais 21 .

No grupo com indicadores sociais mais favoráveis encontram-se os municípios localizados no interior do Estado, onde esse processo descrito foi menos intenso, criando condições no processo de urbanização de uma capacidade de resposta mais adequada no que diz respeito aos serviços básicos.

O regaste histórico das políticas de saúde no âmbito estadual mostra um ciclo positivo para a atenção básica na região metropolitana da década de 1980, com a incorporação de unidades e aumento de resolutividade dessa rede com as Ações Integradas de Saúde (AIS) e Sis- 
tema Unificado e Descentralizado de Saúde (SUDS) e na década de 1990 um processo de municipalização com modulações feitas pelas NOBs, com o aumento dos recursos federais para os municípios, com a instância gestora estadual cada vez mais se eximindo de formular ações para a atenção básica, voltando-se quase que inteiramente para os níveis mais complexos da assistência, deixando a rede básica para a gestão municipal, que com raras exceções não estava habilitada para esta tarefa 22 .

A adequação e a capacidade, por esses municípios, de desenvolver os novos programas PSF e Pacs encontradas nos resultados preliminares deste trabalho são resultantes em grande parte deste processo.

O segundo comentário diz respeito aos resultados encontrados nas diferentes dimensões propostas pelo estudo, não levando em consideração as diferenças observadas na comparação pelos clusters, mas os valores ajustados obtidos em si dos municípios na percepção dos usuários.

As três dimensões que atingem médias ajustadas acima de $70 \%$, valor que pode ser considerado satisfatório, foram: a porta de entrada, o vínculo (ou longitudinalidade) e profissionais, independentemente dos clusters. Se atentarmos para suas definições e questões formuladas, encontraremos nexos entre essas três dimensões caracterizadas pelo conhecimento do usuário dos profissionais, seu tempo de utilização desse tipo de serviço e a possibilidade de ver suas necessidades mais imediatas serem atendidas.
Quando se examinam as outras cinco dimensões Acesso, Coordenação, Orientação comunitária, Enfoque familiar e Elenco de serviços, estas se encontram em limites entre 35\% e $50 \%$ nas médias, valores que podemos chamar de insuficientes. Sem extrapolar na inferência destas dimensões, podemos dizer que estas se constituem em pilares da concepção mais estruturante e complexa da atenção básica nos sistemas de saúde. No entanto, excetuando o Acesso, não são dimensões historicamente valorizadas nos serviços de saúde, não fazendo parte do aprendizado que a população construiu nas suas relações com os serviços. Transformar essa experiência vivida requer forte e duradouro investimento não somente em capacitação, mas um esforço de mudança cultural de profissionais e gestores e sustentabilidade das propostas implantadas. A análise da diferença de percepções encontradas entre usuários e profissionais das dimensões estudadas também reflete essa diferença nas expectativas quanto à atenção desenvolvida, e ela tem sido observada de forma recorrente na literatura ${ }^{23,24}$.

Diante da escassez de estudos abrangentes nesta área e de instrumentos e processos para avaliação de desempenho e organização da atenção básica, os dados e informações coletados neste estudo que permitem abordagens analíticas múltiplas poderão contribuir de forma importante com novos conhecimentos a serem utilizados para as decisões nos diferentes níveis de gestão e no monitoramento e melhoria de nossos serviços.

\section{Colaboradores}

N Ibañez participou na concepção geral, pesquisa e redação final; PC Castro e MCSA Ribeiro, na pesquisa e na metodologia; JSY Rocha, AC Forster, MHD Novaes e AL d'Avila Viana, na pesquisa e revisão. 


\section{Referências}

1. Fausto MCR. Dos programas de medicina comunitária ao Sistema Único de Saúde: uma análise histórica da atenção primária na política de saúde brasileira [tese.] Instituto de Medicina Social da Universidade do Estado do Rio de Janeiro, Rio de Janeiro; 2005.

2. Levcovitz E, Baptista TWF, Uchoa SAC, Nespoli G, Mariani M. Produção de conhecimento em política, planejamento e gestão em saúde e políticas de saúde no Brasil: 1974-2000. Brasília: Organização Pan-Americana da Saúde; 2003. (Série Técnica Projeto de Desenvolvimento de Sistemas e Serviços de Saúde, n. 2).

3. Harzheim E, Alvarez-Dardet C, Ruiz MT, Stein AT Revisão sistemática sobre os aspectos metodológicos das pesquisas em atenção primária. Artigo encaminhado para publicação na Revista da Associação Médica do Rio Grande do Sul; 2004.

4. Almeida, CM, Macinko J, Oliveira ES, Sá PK. Validação de uma metodologia de avaliação rápida das características organizacionais e do desempenho de serviços de atenção básica do SUS em nível local. Relatório Final. Rio de Janeiro: ENSP/Fiocruz; 2004.

5. Arouca ASS. O dilema preventivista. Contribuição para a compreensão da medicina preventiva [tese]. Faculdade de Ciências Médicas da Universidade Estadual de Campinas, Campinas; 1975.

6. Unicef. Brasil. Cuidados Primários de Saúde. Relatório sobre Cuidados Primários de Saúde, Alma-Ata, URSS, 6-12 de setembro de 1978. Brasil; 1979.

7. Tarimo E, Webster EG. Primary health care concepts and challenges in a changing world: Alma-Ata revisited. World Health Organization, Division of Analysis, Research and Assessment, ARA Paper n. 7, 1997.

8. Starfield B. Atenção primária: equilíbrio entre necessidades de saúde, serviços e tecnologia. Tradução: Fidelity Translations. Brasília: Unesco, Ministério da Saúde, 2002.

9. Macinko J, Starfield B, Shy L. The Contribution of Primary Care Systems to Health Outcomes within Organization for Economic Cooperation and Development (OECD) Countries, 1970-1998. Health Serv Res 2003; 38(8):831-65.

10. Cueto M. The origins of primary health care and selective primary health care. Lima: Universidad Peruana Cayetano Heredia, 2003. [acessado em 30 nov. 2005]. Disponível em http://www.globalhealthtrust. org/doc/Word\%20Marcos\%20Cueto.pdf.

11. Banco Mundial. Informe sobre o Desenvolvimento Mundial 1993: Investindo em Saúde. Washington. Banco Mundial; 1993.
12. Almeida CM. As reformas sanitárias nos anos 80 crises ou transição? [tese]. Rio de Janeiro: ENSP/Fiocruz; 1995.

13. Viana ALDA, Fausto MCR. Atenção básica e proteção social: universalismo $\mathrm{x}$ focalismo e espaço nãomercantil da assistência. In Viana ALDA, Elias PE, Ibañez N. Proteção social: dilemas e desafios. São Paulo: Hucitec; 2005. p. 185-201.

14. Paim JS. Descentralização das ações e serviços de saúde no Brasil e a renovação da proposta "saúde para todos". Rio de janeiro: IMS; 1998. (Série Estudos em Saúde Coletiva, n. 175).

15. Sampaio LFR. O papel das Secretarias de Estado da Saúde no acompanhamento e avaliação da atenção primária à saúde. In: CONASS. Progestores. Acompanhamento e avaliação da atenção primária. Material de apoio. Brasília: CONASS, 2004. [acessado em 29 out. 2004] p.7-28. Disponível em: http://www. conass.com.br/off/of_ma/mat_apoio.doc.

16. Kruskall-Wallis \& Kish L. Survey sampling. 3a ed. New York: John Wiley \& Sons, Inc; 1965.

17. Bolfarine H, Bussab WO. Elementos de amostragem. Instituto de Matemática e Estatística da Universidade de São Paulo (versão preliminar), 2000.

18. Cochram WG. Sampling techniques. 3a ed. New York, John Wiley \& Sons, Inc, 1977.

19. Santos M. Metrópole corporativa e fragmentada: o caso de São Paulo. São Paulo: Nobel; 1990.

20. Souza MAA. Uso do território e saúde: refletindo sobre "municípios saudáveis". In: Sperandio AMG, organizadora. O processo de construção da rede de municípios potencialmente saudáveis. Campinas: IPES Editorial; 2004. p. 127-159.

21. Ibañez N, Viana AL. Programa Metropolitano de Saúde: estratégias de implantação. ver Paulista de Hospitais 1986; 10:16-30.

22. Ibañez N. Municipalização e sistema local de saúde: estudo de experiências municipais na implantação do SUS [tese]. Faculdade de Saúde Pública da USP; 1994.

23. Macinko J, Almeida C, Oliveira ES, Sá PK. Organization and delivery of primary health care services in Petrópolis, Brazil. International J of Health Planning and Management 2004; 19:303-17.

24. Novaes HMD. Pesquisa em, sobre e para os serviços de saúde: panorama internacional e questões para a pesquisa em saúde no Brasil. Cad Saúde Pública 2004, 20(sup2):S147-S173.

Artigo apresentado em 27/02/2006

Aprovado em 31/03/2006

Versão final apresentada em 17/04/2006 